\title{
Does proactive personality matter in mobile learning?
}

Rui-Ting Huang, Tzy-Wen Tang, Yi Ping Lee

National Chung Hsing University, Taiwan

Fang-Ying Yang

National Taiwan Normal University

\begin{abstract}
Increasing attention has been paid to mobile learning studies. However, there is still a dearth of studies investigating the moderating effect of proactive personality on mobile learning achievements. Accordingly, the primary purpose of this study is not only to investigate the key elements that could improve the effectiveness and efficiency of mobile learning, but also to examine the moderating role of proactive personality in mobile learning outcomes. The findings indicate that continuance intention will have a positive influence on mobile learning performance, whereas perceived playfulness will have a limited influence on mobile learning outcomes. Moreover, perceived flexibility advantages will positively affect mobile learning continuance intention and perceived playfulness. With respect to the role of perceived usefulness in perceived playfulness, the results indicate that although perceived usefulness has a positive influence on continuance intention, it has a limited impact on perceived playfulness. Finally, the results indicate that proactive personality plays a moderating role in the relationship between perceived playfulness and mobile learning performance, the connection between perceived flexibility advantages and mobile learning continuance intention, the nexus between perceived usefulness and mobile learning continuance intention, as well as the connection between perceived usefulness and playfulness.
\end{abstract}

\section{Introduction}

Probably because emerging mobile technology could play a key role in enhancing individual performance and learning outcomes, the application of mobile technology in organisations and the learning process has been one of the key issues in previous studies (Mouza, \& Barrett-Greenly, 2015). For example, an early review by Chung, Lee, and Kim (2014) suggested that the use of mobile enterprise systems could facilitate employees to improve perceived job performance. Another language learning report by Teodorescu (2015) has shown that the language learning process could be further improved through the use of mobile technology. In light of this, increasing attention has been paid to mobile leaning studies. However, there is still a dearth of studies investigating the moderating effect of proactive personality on mobile learning achievements. Specifically, whether proactive personality could play a key role in reinforcing or weakening mobile learning outcomes has not yet been fully investigated.

With particular respect to the close link between personality traits and learning outcomes, research has shown that personality traits could play a key role in learning achievement. For example, Komarraju, Karau, Schmeck, and Avdic (2011) have found that the big five personality traits, such as conscientiousness and agreeableness, could be positively associated with learning styles, and 'the Big Five together explained $14 \%$ of the variance in grade point average (GPA)' (p. 472). Nevertheless, Erdogan and Bauer (2005) have indicated that proactive personality, 'a unique disposition', is different from the big five personality traits (p. 861). Accordingly, in order to close the gap in prior research, the primary purpose of this study is not only to investigate the key elements that could improve the effectiveness and efficiency of mobile learning, but also to examine the moderating role of proactive personality in mobile learning outcome.

\section{Literature review and hypothesis development Perceived playfulness}

The issues of enjoyment and playfulness in learning have received much attention, owing probably to its pivotal impact on learning achievement (Hamari et al., 2016). In information technology studies, perceived playfulness, similar to the concept of perceived enjoyable, is described as 'the extent to which the individual (a) perceives that his or her attention is focused on the interaction with the Web; (b) is curious during the interaction; and (c) finds the interaction intrinsically enjoyable or interesting' (Padilla-Meléndez, del Aguila-Obra, \& Garrido-Moreno, 2013, p. 308). It has been found that perceived playfulness, an intrinsic 
motivation, could be closely linked to a more positive learning attitude and intention to adopt mobile learning and new technology (Cheng, 2015; Liao, Huang, Chen, \& Huang, 2015; Padilla-Meléndez et al., 2013). For example, Cheng (2015) has shown that perceived enjoyment is one of the key antecedents of mobile learning intention. Liao et al. (2015) added that in a ubiquitous learning context, perceived playfulness would positively affect learning attitude, which in turn could lead to better learning satisfaction. Additionally, it has been shown that perceived playfulness could have a positive influence on mobile learning outcomes (Huang, Jang, Machtmes, \& Deggs, 2012). Accordingly, based on previous reports, this study proposes the following hypothesis

H1: Perceived playfulness will have a positive influence on mobile learning performance.

\section{Mobile learning continuance intention}

It has been found that continuance intention, which refers to learners' continuance intention to adopt mobile learning, could play a key role in determining mobile learning performance. That is, as learners have more positive mobile learning continuance intention, it is likely that they will have better mobile learning performance. The positive connection between continuance intention and individual performance has been well documented in previous research. For example, an early study by Lin (2012) indicates that continuance intention could positively predict web-based learning performance. Another report, by Mohammadyari and Singh (2015), has suggested that e-learning continuance intention could be positively connected with individual performance. Similarly, in mobile learning environments, as learners have more positive mobile learning continuance intention, it is possible that they will have better mobile learning performance. Accordingly, this study proposes the following hypothesis:

H2: Mobile learning continuance intention will have a positive influence on mobile learning performance.

\section{Perceived flexibility advantages}

It has been found that online learning flexibility advantages, which refers to 'a high degree of flexibility in when and where they participate in Internet-based courses' (Arbaugh, 2000, p. 35), could be highly associated with students' online learning adoption (Arbaugh, 2002; Hamzaee, 2005; Hollis \& Madill, 2006). More precisely, some learners are influenced by online learning flexibility advantages, probably because time and place flexibility advantages of online learning could facilitate busy learners to cope with their personal and working activities (Arbaugh, 2000; Huang, Hsiao, Tang, Lien, 2014; Lu, Yang, \& Yu, 2013; Marks, Sibley, \& Arbaugh, 2005). In view of the pivotal influence of perceived flexibility advantages on learning effectiveness and efficiency, several researchers have concentrated on the relationship between perceived flexibility advantages and online learning outcomes (Arbaugh, 2000; Huang et al., 2014; Lu et al., 2013; Marks et al., 2005). For example, an early report by Arbaugh (2000) revealed that the perceived flexibility advantages could play a key part in determining online learning satisfaction. Another review, by Yukselturk and Yildirim (2008), has suggested that the perceived flexibility advantages should be one of the critical factors for online learning satisfaction.

Moreover, in regard to the link between perceived flexibility advantages, playfulness, and continuance intention, Chung and Tan (2004) have suggested that flexibility should be a critical antecedent of perceived playfulness. Chow and Shi (2014) added that learning flexibility could be positively associated with online learning continuance intention. Although previous research has paid some attention to the role of perceived flexibility advantages in mobile learning (Clay, 2011; Evans, 2008; Gedik, Hanci-Karademirci, Kursun, \& Cagiltay, 2012), limited studies have been conducted on the effect of perceived flexibility advantages on perceived playfulness and mobile learning continuance intention. In mobile learning environments, it is likely that the perceived flexibility advantages, which are described as the time and place flexibility advantages of mobile learning, could be closely related to perceived playfulness and mobile learning continuance intention. Accordingly, this study proposes the following hypotheses:

H3: Perceived flexibility advantages will have a positive influence on mobile learning continuance intention.

H4: Perceived flexibility advantages will have a positive influence on perceived playfulness. 


\section{Perceived usefulness}

Previous reports have indicated that the perceived usefulness, which is described as 'the degree to which a person believes that using a particular system would enhance his or her job performance' (Davis, 1989, p. 320), is one of the central elements that could have a positive influence on mobile technology continuance intention and playfulness. For instance, Chung and Tan (2004) have indicated that perceived usefulness could be a key antecedent of perceived playfulness. In addition, Oghuma, Libaque-Saenz, Wong, and Chang (2016) have found that perceived usefulness will positively influence users' continuance intention to use mobile instant messaging. Similarly, in mobile learning environments, it is possible that learners with better perceived usefulness of mobile technology will have more positive mobile learning continuance intention and perceived playfulness. Consequently, based on previous reports, this study proposes the following hypotheses:

H5: Perceived usefulness will have a positive influence on mobile learning continuance intention. H6: Perceived usefulness will have a positive influence on perceived playfulness.

\section{The moderating role of proactive personality}

Proactive personality, which is described as 'someone who is relatively unconstrained by situational forces and who effects environmental change' (Crant, 2000, p. 439), has been one of the focal issues in previous studies. Specifically, more proactive individuals tend to actively identify potential chances, persistently deal with possible problems and take the initiative to bring about changes (Crant, 2000). Erdogan and Bauer (2005) have revealed that proactive people would rather take the initiative to lead changes than passively accept the status quo. Chen (2011) added that 'a proactive personality is characterized by the initiative to improve their current circumstances or to create new ones rather than passively adapting to their present conditions and the ability to effect environmental change' (p. 65). Due probably to the critical role of proactive personality in organisations, numerous studies have paid much attention to its impact on individual performance and organisational outcomes (Claes, Beheydt, \& Lemmens, 2005; Fuller and Marler, 2009). For example, an early report by Seibert et al. (1999) has shown that proactivity personality is one of the key elements that could positively affect employees' earnings, number of promotions and career satisfaction. A study by Fuller and Marler (2009) found that proactive personality could be positively linked to job performance and organisational commitment. Additionally, Ashforth, Sluss, and Saks (2007) have revealed that newcomers' proactive behaviour in organisations could positively predict their learning performance.

Studies have shown that proactive personality could play a moderating role in organisations. For instance, Wang, Hu, Hurst, and Yang (2014) have suggested that proactive personality could moderate the link between career mentoring and job content plateaus. Additionally, Cai and his colleagues (2015) added that proactive personality could moderate the relationship between self-esteem and career exploration. Similarly, in mobile learning environments, it is likely that proactive personality could play a key role in moderating the relationship between key mobile learning factors and outcomes. Accordingly, based on prior suggestions, this study proposes the following research questions and theoretical framework of the study (see Figure 1):

- $\quad$ Research question 1: Will proactive personality moderate the relationship between perceived playfulness and mobile learning performance?

- $\quad$ Research question 2: Will proactive personality moderate the relationship between mobile learning continuance intention and performance?

- $\quad$ Research question 3: Will proactive personality moderate the relationship between perceived flexibility advantage and mobile learning continuance intention?

- $\quad$ Research question 4: Will proactive personality moderate the relationship between perceived flexibility advantage and playfulness?

- $\quad$ Research question 5: Will proactive personality moderate the relationship between perceived usefulness and mobile learning continuance intention?

- Research question 6: Will proactive personality moderate the relationship between perceived usefulness and playfulness? 


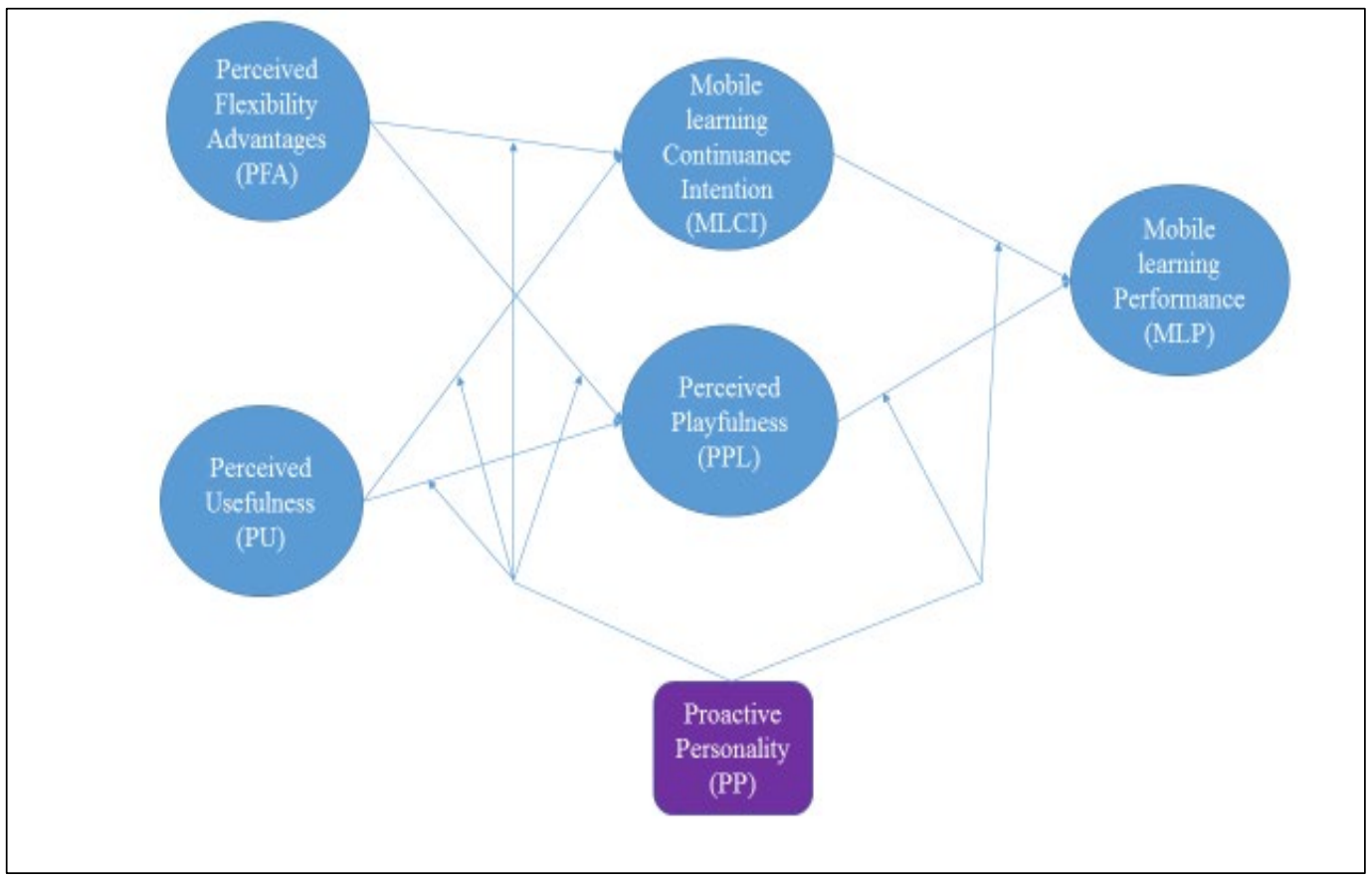

Figure 1. Research framework of the study

\section{Research methodology \\ Demographic data for respondents}

307 undergraduate students with mobile English learning experience took part in this study. Excluding missing data $(n=6)$, male and female participants were 93 and 208, respectively. As shown in Table 1, $60 \%$ of the total respondents had used a mobile phone to learn English before, and the majority of participants were undergraduate business students (4\%). Finally, the mean age of participants was 20.10 (with standard deviation $=2.602$ ).

Table 1

Demographic data for respondents

\begin{tabular}{llcc}
\hline Demographics & Items & Number & Percentage of respondents \\
\hline Gender & Male & 93 & 30 \\
& Female & 208 & 68 \\
College & Missing data & 6 & 2 \\
& Arts and Humanities & 4 & 1 \\
& Business & 137 & 45 \\
& Engineering & 15 & 5 \\
Mobile devices & 132 & 43 \\
& Social Sciences & 19 & 6 \\
& Missing data & 187 & 60 \\
& Mobile phone & 68 & 22 \\
& Notebook computer & 51 & 17 \\
& Others (PDA, electronic dictionaries) & 1 & 1 \\
& Missing data & 292 & 95 \\
& Valid participants & 15 & 5 \\
& Missing data & 20.10 & \\
& Mean age & 2.602 & \\
\hline
\end{tabular}

\section{Data collection}

This study simultaneously gathered data from several colleges and universities in Taiwan. The final number of usable surveys was 307. The participants of this study were undergraduate students who had previously adopted mobile devices to learn English. 


\section{Instrumentation}

This study used a 7-point Likert scale to measure the level of agreement of each construct. Items which evaluated perceived flexibility advantages were adopted from Marks et al. (2005). Sample items were 'Using mobile technology could allow me to arrange my English learning time more easily' and 'Using mobile technology could enable me to arrange English learning schedule more flexibly'. Items which examined perceived usefulness and mobile learning continuance intention were developed from Roca, Chiu, and Martínez (2006). Sample items were 'Using mobile technology to learn English could improve my English learning performance' and 'I will continue to use mobile technology to learn English in the future'. In addition, items which measured perceived playfulness and mobile learning performance were adopted from Huang et al. (2012). Sample items were 'Using mobile technology to learn English is one of my enjoyments' and 'Overall, using mobile technology to learn English helps me improve my English ability’. Finally, items which evaluated proactive personality were taken from Frese, Fay, Hilburger, Leng, and Tag (1997). Sample items were 'No matter what the odds, if I believe in something I will make it happen' and 'Nothing is more exciting than seeing my ideas turn into reality'.

\section{Data analysis and results}

The SPSS and Visual PLS software were used to accomplish the research goals. This study adopted the partial least squares (PLS) analysis, one of the structural equation modelling (SEM) techniques, to examine the data in three different models: full model (FM), low proactive personality model (LPPM) and high proactive personality model (HPPM). Specifically, the full model (FM) contained all participants in this study.

Table 2

Confirmatory factor analysis of each model

\begin{tabular}{|c|c|c|c|c|c|c|c|c|c|c|c|c|}
\hline Items & FM & CR & AVE & $\alpha$ & $\begin{array}{l}\text { High } \\
\text { PP }\end{array}$ & CR & AVE & $\alpha$ & $\begin{array}{l}\text { Low } \\
\text { PP }\end{array}$ & CR & AVE & $\alpha$ \\
\hline PFA1 & .88 & & & & .88 & & & & .83 & & & \\
\hline PFA2 & .92 & & & & .90 & & & & .89 & & & \\
\hline PFA3 & .92 & & & & .90 & & & & .91 & & & \\
\hline PFA4 & .82 & & & & .80 & & & & .80 & & & \\
\hline PFA & & .94 & .79 & .91 & & .92 & .75 & .89 & & .92 & .74 & .88 \\
\hline PU1 & .88 & & & & .89 & & & & .85 & & & \\
\hline PU2 & .90 & & & & .89 & & & & .88 & & & \\
\hline PU3 & .89 & & & & .85 & & & & .90 & & & \\
\hline PU4 & .87 & & & & .85 & & & & .86 & & & \\
\hline PU & & .93 & .79 & .91 & & .92 & .76 & .89 & & .93 & .76 & .89 \\
\hline PPL1 & .86 & & & & .88 & & & & .79 & & & \\
\hline PPL2 & .94 & & & & .92 & & & & .93 & & & \\
\hline PPL3 & .88 & & & & .88 & & & & .84 & & & \\
\hline PPL & & .92 & .80 & .88 & & .92 & .80 & .87 & & .89 & .74 & .81 \\
\hline MLCI1 & .92 & & & & .91 & & & & .91 & & & \\
\hline MLCI2 & .92 & & & & .93 & & & & .89 & & & \\
\hline MLCI3 & .89 & & & & .91 & & & & .79 & & & \\
\hline MLCI & & .94 & .84 & .90 & & .94 & .84 & .90 & & .90 & .75 & .84 \\
\hline MLP1 & .87 & & & & .90 & & & & .77 & & & \\
\hline MLP2 & .88 & & & & .87 & & & & .82 & & & \\
\hline MLP3 & .89 & & & & .91 & & & & .84 & & & \\
\hline MLP4 & .87 & & & & .87 & & & & .80 & & & \\
\hline MLP5 & .90 & & & & .91 & & & & .87 & & & \\
\hline MLP & & .94 & .78 & .93 & & .95 & .79 & .93 & & .91 & .67 & .88 \\
\hline
\end{tabular}

Note. FM, full model; HPP, high proactive personality; LPP, low proactive personality; PFA, perceived flexibility advantages; PPL, perceived playfulness; PU, perceived usefulness; MLCI, mobile learning continuance intention; MLP, mobile learning performance; CR, composite reliability; AVE, average variance extracted; $\alpha$, Cronbach's alpha 
The low proactive personality model (LPPM) included learners with low levels of proactive personality, whereas the high proactive personality model (HPPM) comprised those with high levels of proactive personality. First, in order to assess the adequacy of measurement model, the composite reliability (CR) of each construct and item loadings were used to evaluate the reliability and internal consistency of measuring scales. As shown in Table 2, the CR of each factor was all higher than .80 (Fornell \& Larcker, 1981), and item loadings in different models were all above .70. Hence, it was revealed that the measuring scales were acceptable (Fornell \& Larcker, 1981). In addition, the average variance extracted (AVE) and square root of AVE for each construct were adopted to examine the convergent and discriminant validity. As seen in Table 3, it was found that the measurement model indicated satisfactory convergent and discriminant validity, not only because the AVE of each construct was higher than the minimum acceptable criteria (.50), but also because the square root of AVE for each construct all exceeded correlation values between constructs (Fornell \& Larcker, 1981).

Table 3

Correlations of each construct among different models

\begin{tabular}{lccccc}
\hline \multicolumn{1}{c}{ Full model } \\
\hline Construct & PFA & PU & MLCI & PPL & MLP \\
PFA & .88 & & & & \\
PU & .64 & .88 & & & \\
MLCI & .71 & .63 & .89 & .89 & \\
PPL & .73 & .60 & .60 & .64 & .88 \\
MLP & .68 & .60 & HPP & & \\
\hline
\end{tabular}

\begin{tabular}{llllll}
\hline Construct & & & & & \\
PFA & .86 & & & & \\
PU & .62 & .86 & .91 & .89 & .89 \\
MLCI & .64 & .54 & .59 & .65 & \\
PPL & .71 & .63 & .77 & & \\
MLP & .68 & .55 & LPP & \\
\hline
\end{tabular}

\begin{tabular}{llllll}
\hline Construct & & & & \\
PFA & .86 & & & \\
PU & .50 & .87 & .86 & \\
MLCI & .63 & .57 & .37 & .85 & .81 \\
PPL & .60 & .38 & .65 & .40 & \\
MLP & .50 & .49 &
\end{tabular}

Note. FM, full model; HPP, high proactive personality; LPP, low proactive personality; PFA, perceived flexibility advantages; PPL, perceived playfulness; PU, perceived usefulness; MLCI, mobile learning continuance intention; MLP, mobile learning performance; Diagonal elements are the square root of average variance extracted

Moreover, according to Figures 2 and 3, it was found that hypotheses 2, 3, 4 and 5 were supported by the study findings in different models, whereas hypotheses 1 and 6 were only supported by the study findings in the full model and high proactive personality model. Specifically, in the full model (FM) and high proactive personality model (HPPM), the perceived flexibility advantages, (FM, $\beta=.522, t=9.439$; HPPM, $\beta=.495, t=5.403$ ) and usefulness (FM, $\beta=.299, t=4.440$; HPPM, $\beta=.238, t=2.621)$, which accounted not only for a total of $56.2 \%$ of variance in continuance intention in the full model group, but also for a total of $45.0 \%$ of variance in continuance intention in the high proactive personality model, would have a positive influence on mobile learning continuance intention. Additionally, the perceived flexibility advantages, (FM, $\beta=.591, t=12.614$; HPPM, $\beta=.530, t=8.147$ ) and usefulness (FM, $\beta=.221, t=4.327$; HPPM, $\beta=.301, \mathrm{t}=5.258$ ), which explained a total of $56.6 \%$ of variance in perceived playfulness in the full model group, and a total of $57.2 \%$ of variance in perceived playfulness in the high proactive personality model, would have a positive impact on perceived playfulness. 
Third, with regard to the link between perceived playfulness, mobile learning continuance intention and performance, it was found that mobile learning continuance intention (FM, $\beta=.609, t=9.154$; HPPM, $\beta=$ .593, $t=7.426$ ), and perceived playfulness (FM, $\beta=.278, t=4.021$; HPPM, $\beta=.299, t=3.537$ ), which accounted not only for a total of $65.3 \%$ of variance in mobile learning outcome in the full model group, but also for a total of $65.2 \%$ of variance in mobile learning outcome in the high proactive personality model, would have a positive impact on mobile learning performance. Nevertheless, in the low proactive personality model (LPPM), it was revealed that perceived usefulness was not linked to perceived playfulness $(\beta=.116, t=1.605)$, and perceived playfulness would not have a positive influence on mobile learning performance $(\beta=.193, t=1.588)$.

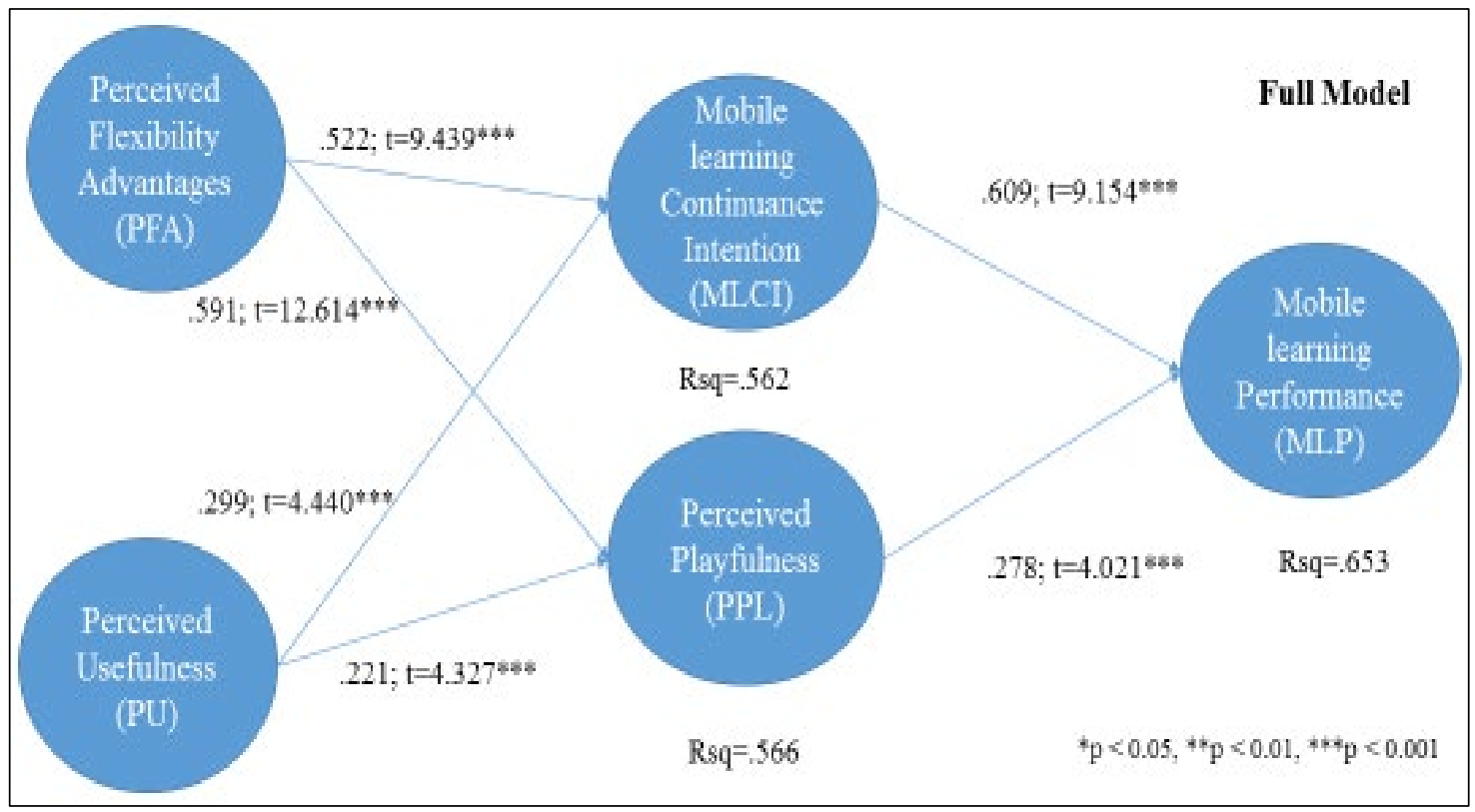

Figure 2. Path coefficient of full model

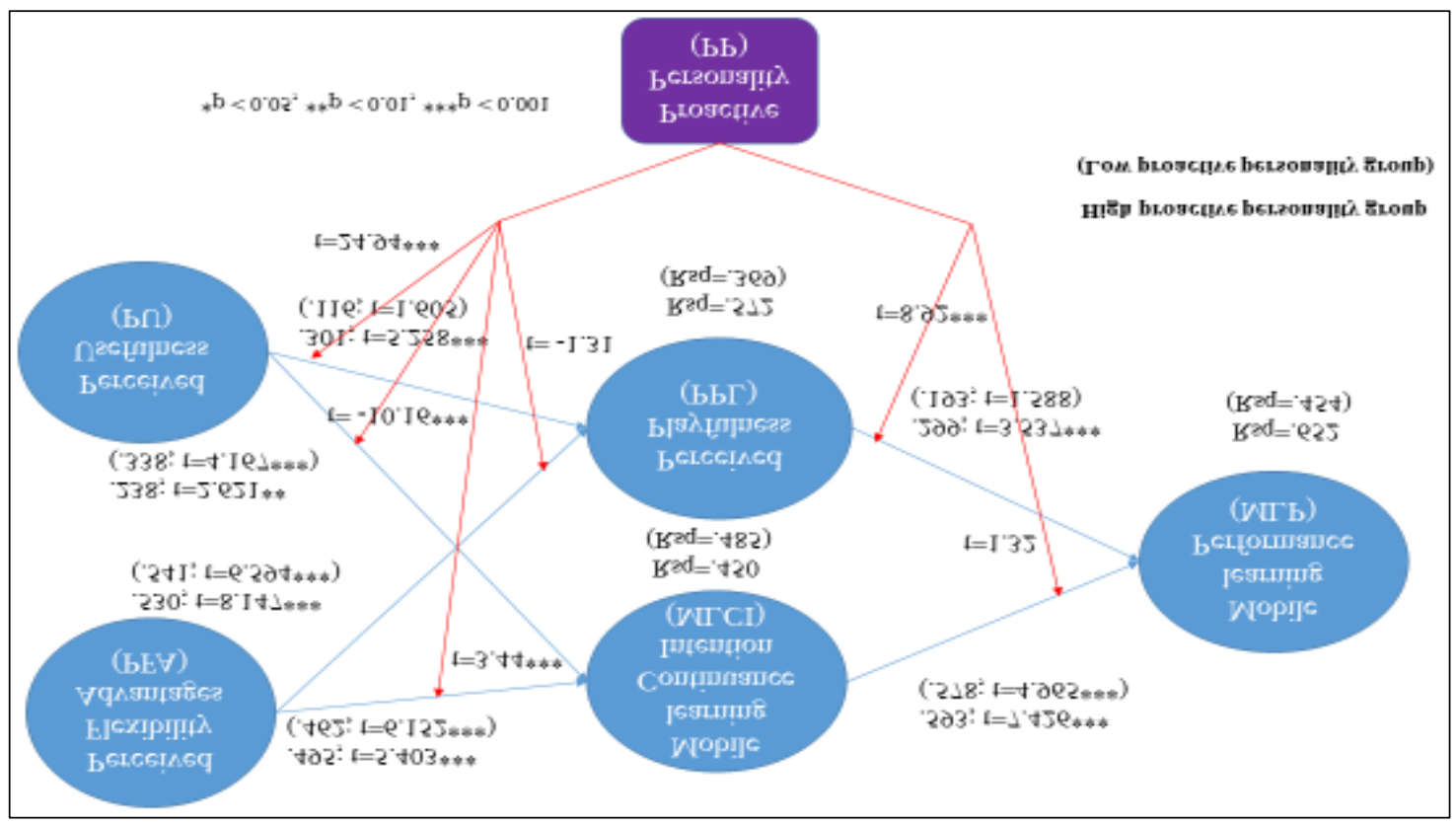

Figure 3. Path coefficient of different groups

Finally, in order to examine the moderating effect of proactive personality on mobile learning outcome, the median score of proactive personality was utilised to categorise 307 participants into two groups: high proactive personality group $(N 1=158)$ and low proactive personality group $(N 2=149)$. This study 
subsequently carried out an analysis of path coefficient comparison, which was put forth by Keil, Tan, Wei, and Saarinen (2000), to investigate whether the moderating effect of proactive personality exists in the relationship between key mobile learning factors and outcomes. The procedures were as follows:

$$
\begin{gathered}
\text { Spooled } \sqrt{\frac{(N h-1) \times S E h^{2}+(N l-1) \times S E l^{2}}{(N h+N l-2)}} \\
t=\frac{(P C h-P C l)}{\frac{\text { Spooled }}{\sqrt{\frac{1}{N h}+\frac{1}{N l}}}}
\end{gathered}
$$

Spooled $=$ pooled estimator for the variance

$t=\mathrm{t}$-statistic with $(\mathrm{Nh}+\mathrm{Nl}-2)$ degrees of freedom

$N h=$ sample size of high proactive personality group

$\mathrm{Nl}=$ sample size of low proactive personality group

$P C h=$ path coefficient in structural model of high proactive personality

$\mathrm{PCl}=$ path coefficient in structural model of low proactive personality

$S E h=$ standard error of path in structural model for high proactive personality

$S E l=$ standard error of path in structural model for low proactive personality

As seen in Table 4, the study finding indicate that proactive personality would moderate the relationship between perceived playfulness and mobile learning performance $(t=8.92, p<0.001)$, the link between perceived flexibility advantages and mobile learning continuance intention $(t=3.44, p<0.001)$, the association between perceived usefulness and mobile learning continuance intention $(t=-10.16, p<0.001)$, as well as the connection between perceived usefulness and playfulness $(t=24.94, p<0.001)$. In addition, proactive personality did not play a moderating role in the link between mobile learning continuance intention and performance $(t=1.32)$, and the relationship between perceived flexibility advantages and perceived playfulness $(t=-1.31)$.

Table 4

Moderating effect of proactive personality

\begin{tabular}{llrrrrr}
$\begin{array}{l}\text { Research } \\
\text { question }\end{array}$ & Path & \multicolumn{2}{c}{$\begin{array}{c}\text { HPP (N1=158) } \\
\text { Path coefficient }\end{array}$} & SE & Path coefficient & SE \\
\hline RQ1 & PPL $\rightarrow$ MLP & .299 & .0845 & .193 & .1215 & $8.92^{* * *}$ \\
RQ2 & MLCI $\rightarrow$ MLP & .593 & .0799 & .578 & .1164 & 1.32 \\
RQ3 & PFA $\rightarrow$ MLCI & .495 & .0916 & .462 & .0751 & $3.44^{* * *}$ \\
RQ4 & PFA $\rightarrow$ PPL & .530 & .0651 & .541 & .0820 & -1.31 \\
RQ5 & PU $\rightarrow$ MLCI & .238 & .0908 & .338 & .0811 & $-10.16^{* * *}$ \\
RQ6 & PU $\rightarrow$ PPL & .301 & .0572 & .116 & .0723 & $24.94^{* * *}$ \\
\hline
\end{tabular}

Note. HPP, high proactive personality; LPP, low proactive personality; PFA, perceived flexibility advantages; PPL, perceived playfulness; PU, perceived usefulness; MLCI, mobile learning continuance intention; MLP, mobile learning performance; ${ }^{*} p<0.05,{ }^{* *} \mathrm{p}<0.01,{ }^{* * *} p<0.001$.

\section{Discussions and implications}

The primary purpose of this study was to investigate the key elements that could improve mobile learning outcomes and further examine the moderating role of proactive personality in mobile learning. The study findings, partly consistent with previous reports (Chow \& Shi, 2014; Huang et al., 2012; Marks et al., 2005), indicate that continuance intention will have a positive influence on mobile learning performance, whereas perceived playfulness will have a limited influence on mobile learning outcome. Nevertheless, the importance of perceived playfulness in learning outcomes should not be underestimated, because as learners enjoy mobile learning and would like to adopt mobile learning, it is likely that they will have better learning performance. In order to improve mobile learning performance, more efforts should be directed towards improving mobile learning playfulness and continuance intention. For example, game-based 
mobile learning could be another solution to help learners have better continuance intention and more fun with mobile learning (Hamari et al., 2016).

Moreover, the study findings are congruent with previous suggestions (Chow \& Shi, 2014; Lu et al., 2013; Marks et al., 2005), which reveal that perceived flexibility advantages will positively affect mobile learning continuance intention and perceived playfulness. With respect to the role of perceived usefulness in perceived playfulness, the study results, partly in line with previous reports (Chung \& Tan, 2004; Oghuma et al., 2016), indicate that although perceived usefulness has a positive influence on continuance intention, it has a limited impact on perceived playfulness. In other words, regardless of the impact of proactive personality on mobile learning, the perceived flexibility advantage of mobile technology is a critical element which could facilitate learners to have better mobile learning continuance intention and perceived playfulness. By contrast, as learners have lower levels of proactive personality, perceived usefulness will only influence mobile learning continuance intention. Nonetheless, in order to enhance the quality of mobile learning, it is important that the central role of perceived usefulness in mobile learning should not be underestimated, and more attention should be paid to the impacts of perceived flexibility advantages and usefulness on mobile learning outcome, mainly because the usefulness and flexibility advantages of mobile technology, beneficial for learners, could facilitate them to have better mobile learning performance. For example, it is suggested that learning institutions could provide learners with mobile technology and mobile learning programs in order to enhance continuous adoptions and performance of mobile learning.

Last but not least, the study findings, partly consistent with previous suggestions (Cai et al., 2015; Wang et al., 2014), indicate that proactive personality will play a moderating role in the relationship between perceived playfulness and mobile learning performance, the connection between perceived flexibility advantages and mobile learning continuance intention, the nexus between perceived usefulness and mobile learning continuance intention, as well as the connection between perceived usefulness and playfulness. More specifically, learners with higher levels of proactive personality could have better association between perceived playfulness and mobile learning performance, stronger connection between perceived flexibility advantages and mobile learning continuance intention, better links between perceived usefulness and playfulness, as well as a weaker relationship between perceived usefulness and mobile learning continuance intention than those with lower levels of proactive personality. More efforts should be devoted to encouraging learners with higher levels of proactive personality to take mobile learning, mainly because they are more likely to achieve better mobile learning outcomes. Nevertheless, with respect to those with lower levels of proactive personality, more attention should be paid to the impacts of perceived usefulness and flexibility advantages on mobile learning, mainly because the usefulness and flexibility advantages of mobile technology could help them have better mobile learning continuance intention, which in turn could result in more preferable mobile learning achievements. For example, it is suggested that institutional policy-makers, professional development staff, curriculum designers or academic staff should consider offering learners with lower levels of proactive personality free training programs so that they become more familiar with the usefulness and flexibility advantages of mobile technology.

\section{Limitations and future research}

There are a few limitations in this study. First, care should be taken with specific regard to the interpretation of study findings, due mainly to the limited sample size and cross-sectional data. It is suggested that more studies should be conducted on investigating the moderating impact of proactive personality on mobile learning outcomes. In addition, the age and gender differences in mobile learning outcomes were neglected in this study. In order to have better mobile learning designs that could satisfy different age and gender groups, it is important that more research should be done on the effects of age and gender differences on mobile learning outcomes. Finally, this study did not investigate the influences of learning supports and self-regulated learning on mobile learning performance. In order to improve mobile learning achievements, it is critical that more attention be paid not only to the connection between mobile learning supports and outcome, but also to the link between critical mobile learning factors and personality traits related to selfregulated learning.

In conclusion, the study results have not only added to the body of knowledge in mobile learning, but also proved the moderating role of proactive personality in mobile learning. In order to improve the effectiveness and efficiency of mobile learning, practitioners and researchers should focus on the moderating role of proactive personality in mobile leaning outcomes. 


\section{References}

Arbaugh, J. B. (2000). Virtual classroom characteristics and student satisfaction with internet-based MBA courses. Journal of Management Education, 24(1), 32-54. doi:10.1177/105256290002400104

Arbaugh, J. B. (2002). Managing the on-line classroom: A study of technological and behavioral characteristics of web-based MBA courses. The Journal of High Technology Management Research, 13(2), 203-223. doi:10.1016/S1047-8310(02)00049-4

Ashforth, B. E., Sluss, D. M., \& Saks, A. M. (2007). Socialization tactics, proactive behavior, and newcomer learning: Integrating socialization models. Journal of Vocational Behavior, 70(3), 447462. doi:10.1016/j.jvb.2007.02.001

Cai, Z., Guan, Y., Li, H., Shi, W., Guo, K., Liu, Y., ... Hua, H. (2015). Self-esteem and proactive personality as predictors of future work self and career adaptability: An examination of mediating and moderating processes. Journal of Vocational Behavior, 86, 86-94. doi:10.1016/j.jvb.2014.10.004

Chen, W.-J. (2011). Innovation in hotel services: Culture and personality. International Journal of Hospitality Management, 30(1), 64-72. doi:10.1016/j.ijhm.2010.07.006

Cheng, Y.-M. (2015). Towards an understanding of the factors affecting m-learning acceptance: Roles of technological characteristics and compatibility. Asia Pacific Management Review, 20(3), 109-119. doi:10.1016/j.apmrv.2014.12.011

Chow, W. S., \& Shi, S. (2014). Investigating students' satisfaction and continuance intention toward elearning: an extension of the expectation - Confirmation model. Procedia - Social and Behavioral Sciences, 141, 1145-1149. doi:10.1016/j.sbspro.2014.05.193

Chung, J., \& Tan, F. B. (2004). Antecedents of perceived playfulness: an exploratory study on user acceptance of general information-searching websites. Information \& Management, 41(7), 869-881. doi:10.1016/j.im.2003.08.016

Chung, S., Lee, K. Y., \& Kim, K. (2014). Job performance through mobile enterprise systems: The role of organizational agility, location independence, and task characteristics. Information \& Management, 51(6), 605-617. doi:10.1016/j.im.2014.05.007

Claes, R., Beheydt, C., \& Lemmens, B. (2005). Unidimensionality of abbreviated proactive personality scales across cultures. Applied Psychology: An International Review, 54, 476-489. doi:10.1111/j.1464-0597.2005.00221.x

Clay, C. A. (2011). Exploring the use of mobile technologies for the acquisition of clinical skills. Nurse Education Today, 31(6), 582-586. doi:10.1016/j.nedt.2010.10.011

Crant, J. M. (2000). Proactive behavior in organizations. Journal of Management, 26(3), 435-462. doi:10.1177/014920630002600304

Davis, F. D. (1989). Perceived usefulness, perceived ease of use, and user acceptance of information technology. MIS Quarterly, 13(3), 319-340. doi:10.2307/249008

Erdogan, B., \& Bauer, T. N. (2005). Enhancing career benefits of employee proactive personality: The role of fit with jobs and organizations. Personnel Psychology, 58, 859-891. doi:10.1111/j.17446570.2005.00772.x

Evans, C. (2008). The effectiveness of m-learning in the form of podcast revision lectures in higher education. Computers \& Education, 50(2), 491-498. doi:10.1016/j.compedu.2007.09.016

Fornell, C., \& Larcker, D. F. (1981). Evaluating structural equation models with unobservable and measurement error. Journal of Marketing Research, 18(1), 39-50. doi:10.2307/3151312

Frese, M., Fay, D., Hilburger, T., Leng, K., \& Tag, A. (1997). The concept of personal initiative: Operationalization, reliability and validity in two German samples. Journal of Organizational and Occupational Psychology, 70, 139-161. doi:10.1111/j.2044-8325.1997.tb00639.x

Fuller J. B., \& Marler, L. E. (2009). Change driven by nature: A meta-analytic review of the proactive personality literature. Journal of Vocational Behavior, 75, 329-345. doi:10.1016/j.jvb.2009.05.008

Gedik, N., Hanci-Karademirci, A., Kursun, E., \& Cagiltay, K. (2012). Key instructional design issues in a cellular phone-based mobile learning project. Computers \& Education, Volume 58(4), 1149-1159. doi:10.1016/j.compedu.2011.12.002

Hamari, J., Shernoff, D. J., Rowe, E., Coller, B., Asbell-Clarke, J., \& Edwards, T. (2016). Challenging games help students learn: An empirical study on engagement, flow and immersion in game-based learning. Computers in Human Behavior, 54, 170-179. doi:10.1016/j.chb.2015.07.045

Hamzaee, R. G. (2005). A survey and a theoretical model of distance education programs. International Advances in Economic Research, 11(2), 215-229. doi:10.1007/s11294-005-3017-6

Hollis, V., \& Madill, H. (2006). Online learning: The potential for occupational therapy education. Occupational Therapy International, 13(2), 61-78. doi:10.1002/oti.209 
Huang, R-T., Hsiao, C-H., Tang, T-W., \& Lien, T-C. (2014). Exploring the moderating role of perceived flexibility advantages in mobile learning continuance intention (MLCI). The International Review of Research in Open and Distance Learning, 15(3), 140-157. Retrieved from http://www.irrodl.org/index.php/irrodl/article/view/1722/2902

Huang, R-T., Jang, S-J., Machtmes, K., \& Deggs, D. (2012). Investigating the roles of perceived playfulness, resistance to change, and self-management of learning in mobile English learning outcome. British Journal of Educational Technology, 43(6), 1004-1015. doi:10.1111/j.14678535.2011.01239.X

Keil, M., Tan, B. C. Y., Wei, K. K., \& Saarinen, T. (2000). A cross-cultural study on escalation of commitment behavior in software projects. MIS Quarterly, 24(2), 299-325. doi:10.2307/3250940

Komarraju, M., Karau, S. J., Schmeck, R. R., \& Avdic, A. (2011). The Big Five personality traits, learning styles, and academic achievement. Personality and Individual Differences, 51(4), 472-477. doi:10.1016/j.paid.2011.04.019

Liao, Y.-W., Huang, Y.-M., Chen, H.-C., \& Huang, S.-H. (2015). Exploring the antecedents of collaborative learning performance over social networking sites in a ubiquitous learning context. Computers in Human Behavior, 43, 313-323. doi:10.1016/j.chb.2014.10.028

Lin, W.-S. (2012). Perceived fit and satisfaction on web learning performance: IS continuance intention and task-technology fit perspectives. International Journal of Human-Computer Studies, 70(7), 498507. doi:10.1016/j.ijhcs.2012.01.006

Lu, J., Yang, J., \& Yu, C.-S. (2013). Is social capital effective for online learning? Information \& Management, 50(7), 507-522. doi:10.1016/j.im.2013.07.009

Marks, R. B., Sibley, S. D., \& Arbaugh, J. B. (2005). A structural equation model of predictors for effective online learning. Journal of Management Education, 29(4), 531-563. doi:10.1177/1052562904271199

Mohammadyari, S., \& Singh, H. (2015). Understanding the effect of e-learning on individual performance: The role of digital literacy. Computers \& Education, 82, 11-25. doi:10.1016/j.compedu.2014.10.025

Mouza, C., \& Barrett-Greenly, T. (2015). Bridging the app gap: An examination of a professional development initiative on mobile learning in urban schools. Computers \& Education, 88, 1-14. doi:10.1016/j.compedu.2015.04.009

Oghuma, A. P., Libaque-Saenz, C. F., Wong, S. F., \& Chang, Y. (2016). An expectation-confirmation model of continuance intention to use mobile instant messaging. Telematics and Informatics, 33(1), 34-47. doi:10.1016/j.tele.2015.05.006

Padilla-Meléndez, A., del Aguila-Obra, A. R., \& Garrido-Moreno, A. (2013). Perceived playfulness, gender differences and technology acceptance model in a blended learning scenario. Computers \& Education, 63, 306-317. doi:10.1016/j.compedu.2012.12.014

Roca, J. C., Chiu, C. M., \& Martínez, F. J. (2006). Understanding e-learning continuance intention: An extension of the technology acceptance model. International Journal of Human-Computer Studies, 64(8), 683-696. doi:10.1016/j.ijhcs.2006.01.003

Teodorescu, A. (2015). Mobile learning and its impact on business English learning. Procedia - Social and Behavioral Sciences, 180, 1535-1540. doi:10.1016/j.sbspro.2015.02.303

Wang, Y.-H., Hu, C., Hurst, C. S., \& Yang, C.-C. (2014). Antecedents and outcomes of career plateaus: The roles of mentoring others and proactive personality. Journal of Vocational Behavior, 85(3), 319328. doi:10.1016/j.jvb.2014.08.003

Yukselturk, E., \& Yildirim, Z. (2008). Investigation of interaction, online support, course structure and flexibility as the contributing factors to students' satisfaction in an online certificate program. Educational Technology \& Society, 11(4), 51-65. Retrieved from http://www.ifets.info/journals/11_4/5.pdf

Corresponding author: Rui-Ting Huang, rthuang0324@dragon.nchu.edu.tw

Australasian Journal of Educational Technology (c) 2017.

Please cite as: Huang, R.-T., Tang, T.-W., Lee, Y. P., \& Yang, F.-Y. (2017). Does proactive personality matter in mobile learning? Australasian Journal of Educational Technology, 33(2), 86-96. https://doi.org/10.14742/ajet.2896 